\title{
La democracia en los microestados del Caribe Oriental: un análisis de su viabilidad*
}

\author{
Rita Giacalone de Romero
}

Las luchas de liberación y la democracia en el Caribe sufrieron un rudo golpe en 1983 con la intervención estadunidense que puso fin al experimento sociopolítico del Movimiento Nueva Joya (New Jewel Movement, NJM) en Granada, volviéndola al redil en que ya se encontraban instaladas las islas hermanas de Dominica, Santa Lucía y San Vicente. Esta visión, sin embargo, necesita para su verdadera comprensión un análisis de cuál es y ha sido la situación de la democracia en ellas desde las vísperas de su independencia política tan reciente y esto es lo que intentaremos hacer en este trabajo. Granada, Dominica, Santa Lucía y San Vicente son cuatro microestados del Caribe oriental que se hallan en el área más cercana a las costas venezolanas. De los cuatro, Dominica es el de mayor tamaño $\left(750 \mathrm{~km}^{2}\right) \mathrm{y}$, a la vez, el de menor población (estimada en 83.000 en 1980); ${ }^{1}$ dándose el fenómeno de que en los otros, a medida que se reducen las dimensiones, aumenta el número de habitantes: Santa Lucía, $616 \mathrm{~km}^{2}$ y 123000 habitantes, y San Vicente, $389 \mathrm{~km}^{2}$ con una población de 124000 (estimada en 1981). Granada no se ajusta exactamente a esta tendencia pues con $344 \mathrm{~km}^{2}$ alberga una población de 109000 habitantes (1981). Estas fueron las últimas islas ocupadas por los europeos en las Antillas Menores y pasaron de manos de colonos franceses a las de los ingleses en 1763 por el Tratado de Paris. ${ }^{2}$

Todas ellas obtuvieron su independencia de Inglaterra en los años setenta, luego de un periodo relativamente corto como estados asociados a Gran Bretaña, y su situación es una de las más difíciles y vulnerables dentro del Caribe tanto en lo político como en lo económico y social. Su ubicación geopolítica en un área de influencia directa de Estados Unidos y entre una potencia europea interesada en retener sus dominios, Francia, al norte, y una nación latinoamericana petrolera interesada en preservar la estabilidad política en sus vecindades, Venezuela, al sur, ha contribuido, sin embargo, para que se vuelquen en ellas volúmenes de ayuda financiera directa e indirecta, que noguardan proporción ni con su tamaño ni con su población, ni menos con la protección de alguna producción de interés estratégico. Analizaremos, primero, los problemas planteados por su estatus como asociados de Inglate-

\footnotetext{
* Trabajo presentado en el Seminario "Las luchas de liberación y la democracia en el Caribe". XVI Congreso Latinoamericano de Sociología, Universidad del Estado de Río de Janeiro, Brasil, 2 a 7 de marzo de 1986.

' Latin America and Caribbean 1984 (Essex); World of Information, 1984, citado en Andres Serbín. "El Caribe Oriental: las secuelas de Grenada", Nueva Sociedad, 76, marzo-abril 1985 , p. 120.

2 John E. Adams, "Union Island, West Indies: An Historical and Geographical Sketch"., Caribbean Studies, vol. 18, núms. 3 y 4, oct. 1978 enero 1979, p. 14-15.
} 
rra, que las empujaron a buscar la independencia política, y el modelo político que heredaron entonces; sintetizaremos luego su evolución sociopolítica postindependentista, viendo cada una de sus experiencias por separado, para, en tercer lugar, discutir el problema de la democracia dentro de un cuadro general de viabilidad política subsidiada.

En cuanto a la forma jurídica del estado asociado, por la cual pasaron estas islas entre 1967 (excepto San Vicente, que lo hizo desde 1969) y la fecha en que accedieron a la independencia, ha sido caracterizada como una relación "superordinado-subordinado" entre dos entidades, "una de las cuales es independiente y soberana y ejerce, por mutuo acuerdo entre ambas partes, cierto grado de autoridad o dominio en determinadas áreas sobre la otra, que no disfruta de soberanía plena sino que es una entidad autónoma". ${ }^{3}$ La ley británica que estableció este estatus fue el Acta de las Indias Occidentales de 1967, que reunió los resultados de discusiones previas con los distintos gobiernos locales y aún con sectores opositores reconocidos, pero su falta de ratificación mediante referendum explica por qué el Comité de Descolonización de las Naciones Unidas no lo consideró un arreglo totalmente satisfactorio, ${ }^{4}$ a pesar de que el sistema permite la terminación unilateral de la asociación por cualquiera de los dos estados vinculados. El segundo paso, luego de la aprobación de la ley, fue la promulgación por parte de Inglaterra de una constitución individual para cada uno de estos estados, o sea que cada una de estas entidades quedó vinculada en forma directa e individual con su metrópolis, pero no entre ellas. Las constituciones son esencialmente idénticas, aunque pueden existir variaciones locales, y constituyen documentos juridicos muy elaborados. En cuanto a ciudadanía, por ejemplo, los nacidos en estos estados son, a la vez, súbditos británicos y de sus islas pero no pueden emigrar libremente a Inglaterra. Salvo en materia de defensa y relaciones exteriores, las leyes del parlamento británico no son aplicables en los estados asociados, a no ser que sus legislaturas así lo soliciten.

Durante este periodo intermedio entre la situación colonial y la independencia se hicieron patentes ya los problemas que afectarían a estos microestados en el periodo postindependentista. Uno especifico y producto de la ambigüedad de su situación fue el desacuerdo entre los gobiernos locales y el metropolitano con respecto al comercio y la inmigración entre las islas e Inglaterra, rubros en que Londres se mostraba renuente a ampliar la circulación en momentos en que negociaba su ingreso al Mercado Común Europeo y más aún después de su acceso a éste en 1973. Los sectores dirigentes de los microestados percibían la actitud de Gran Bretaña como encaminada a desligarse en forma rápida de sus obligaciones para con ellos y, a consecuencia de esto, volvieron a interesarse en la posibilidad de una integración política con sus hermanos mayores dentro del Caribe de habla inglesa. ${ }^{s}$ La Declaración de Granada firmada el 25 de julio de 1971 por Dominica, Granada, Guyana, St. Kitts-Nevis, Santa Lucía y San Vicente, estableció, por lo tanto, un acuerdo preliminar para la creación de una unión política entre los

\footnotetext{
${ }^{3}$ 'Angel Calderón Cruz, "Modelos de libre asociación en el Caribe", en A. Calderón Cruz, ed. Problemas del Caribe contemporáneo, Río Piedras, Instituto de Estudios del Caribe, Universidad de Puerto Rico, 1979, p. 153.

4 Ibid., p. 158-159.

5 Rosina Wiltshire, "Mini-States, Dependency and Regional Integration in the Caribbean", en Vaughan A. Lewis, ed. Size, Self-Determination and International Relations: The Caribbean, Mona, Jamaica: ISER, UWI, 1976 p. 111-112.
} 
signatarios. El intento fracasó cuando Trinidad, en el clima posterior a los sucesos del Poder Negro en 1970, se negó a entrar en el acuerdo. Rápidamente los microestados se retiraron por temor a ser absorbidos por Guyana, el único estado mayor que seguía interesado en este arreglo.

Uno de los principales problemas de este periodo lo constituyó el mantenimiento de "una superestructura politica masiva y una burocracia expansiva" con los limitados recursos económicos a disposición de sus gobiernos. ${ }^{6}$ Buena parte de estos gastos se cubrian con ayuda financiera británica; así entre 1967 y 1972 el déficit presupuestario de los seis estados asociados a Inglaterra en el Caribe (Dominica, Granada, Santa Lucía, San Vicente, Antigua y St. Kitts-Nevis-Anguila) pasó de $5.3 \mathrm{mi}$ llones de dólares del Caribe Oriental a 12.5 millones. Al mismo tiempo se observa que la ayuda de Inglaterra al gasto corriente bajó de $7.5 \mathrm{mi}$ llones a 4.6 millones de esos mismos dólares, por cuanto el gobierno inglés puso mayor énfasis en sus aportes al presupuesto de capital para las, islas. A primera vista esto podría significar que éstas, aunque deficitarias, estaban reduciendo su dependencia de la ayuda británica pero, en realidad, estaban pasando gastos del presupuesto corriente al de capital y, por lo tanto, recursos que aparentemente iban a servir al financiamiento de su desarrollo estaban siendo absorbidos por el mantenimiento de una cabeza gigantesca que drenaba el cuerpo sobre el que se apoyaba. Esto además contribuía a generar descontento por el control que la Tesorería Británica mantenía sobre el aparato financiero del estado asociado, en virtud, justamente, de la ayuda presupuestaria que le prestaba y que, a ojos del gobierno local, chocaba con la autonomía en el ámbito de los asuntos internos. ${ }^{7}$

Poco a poco se fue haciendo evidente que los recursos y la disposición de Inglaterra de seguirlos invirtiendo en estos estados no eran suficientes y que sus gobiernos deberian recurrir a la atracción de fondos internacionales bajo la forma de ayuda, dado que carecían de reservas y de crédito para negociar a otro nivel. ${ }^{8}$ Requisito para el acceso a estos fondos era su constitución en estados políticamente independientes y hacia eso se orientaron los esfuerzos de los dirigentes políticos locales, en especial a partir de la decisión de Granada de independizarse en 1974. Un año más tarde, en una conferencia de jefes de gobierno de la Comunidad del Caribe ( CARICOM), se aprobó en forma unánime iniciar tentativas para alcanzar el estatus de naciones independientes para los cinco estados asociados que subsistían. ${ }^{9}$ Los tres que lo conseguirían primero, en 1978 y 1979, serian Dominica, Santa Lucia y San Vicente.

Las constituciones nacionales que entraron en vigencia al producirse la independencia política de cada uno de estos microestados establecieron un sistema político basado en el llamado "modelo Westminster" de democracia parlamentaria. ${ }^{10}$ Este modelo perpetuaba, por una parte,

"George C. Abbott, "The Associated States and Independence", Journal of Interamerican Studies and World Affairs, vol. 23, núm. I Febrero 1981, p. 77-78.

7 T. Thorndike, "The Politics of Inadequacy. A Study of the Associated Statehood Negotiations and Constitutional Arrangements for the Eastern Caribbean, 1965-1967", Social and Economic Studies, vol. 28, núm. 3, Sept. 1979, p. 613.

B Abbott, op. cit., p. 82-83.

9 Thorndike, op. cit., p. 614 .

10 Sobre este modelo politico véase Ann Spackman, Constitutional Development of the West Indies, 1922-1968, St. Lawrence, Caribbean Universities Press, 1975, Prefacio e Introducción. 
una serie de limitaciones con respecto a la vida independiente de las nuevas naciones y, por otra, el excesivo centralismo y el papel dominante del poder ejecutivo dentro de la estructura política. En lo que se refiere al primer aspecto, se mantuvo la forma monárquica de gobierno, con un representante protocolar, el gobernador general, que aún aparecía como nominando, designando o legalizando con su existencia el aparato político que pretende ser independiente aunque esté reconociendo desde su mismo nacimiento que está "condicionado" por elementos externos que le otorgan su legalidad y esto se nota también en el poder judicial, donde la apelación de última instancia se eleva a un órgano, el Consejo Privado Británico, situado fuera del espacio nacional y sobre el cual el estado independiente carece de control. En cuanto al segundo aspecto, a lo largo de toda la época colonial la base del poder había permanecido inalterable, centrada en la figura del representante de la corona británica. Con la constitución de independencia se retuvo ese poder decisivo, centralizado ahora en la figura del primer ministro. Este controla en forma casi absoluta dos de los tres poderes, el ejecutivo y el legislativo, mientras no se produzca una revuelta de su propio partido o una coalición de los sectores opositores.

Una limitante importante es el hecho de que el "modelo Westminster" se ha insertado aquí en una tradición política ajena a las premisas del modelo. ${ }^{11}$ En el Caribe de habla inglesa el gobierno es el eje en torno al cúal gira buena parte de la vida social y económica del estado, y de él se espera que intervenga activamente en todo tipo de problema, lo que le otorga un poder mucho mayor que el que le asigna el modelo británico. En un entorno inseguro y de escasos recursos se exacerba la tendencia de la masa a centrar sus demandas de bienestar en la imagen redentora del político local, al que se transfieren características de "paternalismo" que antes se atribuian al gobierno imperial. ${ }^{12}$ De esta forma, coinciden elementos de la tradición política con otros del "modelo Westminster" para reforzar un estilo autoritario y personalista de gobierno. ${ }^{13}$

\section{Granada}

La independencia de Granada se produjo en un clima de desacuerdo que preanunciaba quizás los sucesos que cinco años después culminarian en el primer movimiento revolucionario del Caribe de habla inglesa. El descontento se debía a la decisión del premier granadino, Eric Gairy, de pedir la independencia de la isla sin atravesar por las distintas etapas previstas, según las cuales debía realizarse un referendum y obtenerse dos tercios de los votos a favor. ${ }^{14}$ En lugar de esto Gairy llegó a un acuerdo con el gobierno inglés por el cual si él ganaba una elección general teniendo en su plataforma el tema de la independencia, ese go-

$"$ Ibid. También pueden consultarse Fred Phillips, Freedom in the Caribbean, Dobbs Ferry, NY: Oceana Publications, 1977 y Allen Lewis. "The Separation of Power: Its Relevance for Parliamentary Government in the Caribbean", West Indian Law Journal, oct. 1978.

12 Carl Stone, Stratification and Political Change in Trinidad and Jamaica, Beverly Hills, CA, Sage Publications, 1972, p. 9-10.

13 George K. Danns, "Leadership and Corruption: An Analysis of Emergent PostColonial Rule in the Caribbean", Georgetown, 1980, p. 16.

14 W. Richard Jacobs, "The Movement Towards Grenadian Independence", en Independence for Grenada. Myth or Reality? St. Augustine, Tr., IIR, UWI, 1974, p. 26. 
bierno terminaría su asociación con Granada. El acuerdo se mantuvo secreto y no fue sino hasta casi la víspera de la elección de 1972 cuando el premier hizo pública su intención de proceder a obtener la independencia si su partido, el Partido Laborista Unido de Granada (Grenada's United Labour Party, GUL̈P), ganaba las elecciones. Recién en octubre de 1972 se anunció que debido a ese triunfo electoral no habría referendum. Los primeros en reaccionar fueron los sectores de clase media, la Cámara de Comercio y distintos sindicatos controlados por el opositor Partido Nacional de Granada (Grenada National Party GNP). En mayo de 1973 estos llamaron a una huelga general en contra de las negociaciones sobre independencia que se estaban efectuando en Londres. La oposición a éstas se basaba en consideraciones relativas al costo de mantener un aparato estatal independiente y a la convenencia de independizarse mediante alguna forma de integración con otras islas del área, ${ }^{15}$ pero más que nada se debía al carácter del gobierno de Gairy que, desde la conversión de Granada en estado asociado, había impuesto un control con características dictatoriales en la isla, bajo el cual se acentuaban en especial los problemas de corrupción. ${ }^{16}$

Para noviembre de 1973 se produjo una escalada en la acción para impedir la independencia bajo Gairy, en la cual colaboraron sectores de comerciantes y obreros urbanos, más un nuevo movimiento político de reciente creación inspirado por un grupo de jóvenes universitarios vinculados ideológicamente al Poder Negro, el Movimiento Nueva Joya, dirigido por Maurice Bishop y Unison Whiteman. ${ }^{17}$ Sus líderes, aunque no tuvieron un papel decisivo en la huelga que se declaró por cuanto carecían de base sindical, presentaron un documento en el que detallaban las razones por las cuales Gairy debía renunciar antes del 1 de enero como pedían los huelguistas: abuso del sistema legal, confiscación de la emisora de radio para transformarla en un ente propagandístico del gobierno, destrucción del sistema de salud pública, etc. ${ }^{18}$ Las consecuencias de este documento no se hicieron esperar y pronto ocurrieron dos hechos que pueden considerarse la respuesta del gobierno: el ataque físico y encarcelamiento de los dirigentes del NJM y, en enero de 1974, durante una manifestación antigubernamental, la muerte alevosa del comerciante Rupert Bishop, padre de Maurice. ${ }^{19} \mathrm{~A}$ comienzos de febrero, con la independencia fijada para el día 7 de ese mes, un grupo de la Conferencia de Iglesias del Caribe viajó a la isla para tratar, sin éxito, de mediar en la situación. A finales de ese mes, sin haber obtenido su finalidad de impedir la independencia y obligar a Gairy a renunciar, el movimiento comenzó a ceder. ${ }^{20}$ Para ayudar a Gairy a solucionar la crisis, Inglaterra otorgó a su gobierno una donación de 100000 libras esterlinas. ${ }^{21}$

is Gairy habia contemplado tambièn esta posibilidad con Trinidad, Coard Papers, Grenada Constitutional Conference, GCC, 1973-7th Plenary Session, p. 6, citado en Ibid.

${ }^{16}$ Sobre su carrera política véase Archie Singham, The Hero and the Crowd in a Colonial Polity, New Haven, Yale University Press, 1968.

17 Jacobs, op. cit., p. 23-26.

18 D. Sinclair DaBreo, The Grenada Revolution, Castries, St. Lucia, MAPS, 1979, p. 61-66.

19 Sobre las detenciones véase Ibid., p. 76-81 y sobre la muerte de Rupert Bishop, Trinidad Guardian, enero 23, 1974.

${ }^{20}$ Trinidad Guardian, febrero 4, 1974 y Advocate News, febrero 22, 1974.

${ }^{21}$ EPICA Task Force, Grenada. The Peaceful Revolution, Washington, EPICA, 1982, p. 47. 
Después de los sucesos de 1973 y 1974, el. NJM, creado de la fusión de dos grupos populistas de orientación antimperialista, fue evolucionando con la inclusión de elementos marxistas ortodoxos, lo que haría que en 1975 Trevor Munroe lo describiera como "un grupo nacionalista revolucionario con un ala marxista leninista en desarrollo gradual..."22 En el periodo de agitación antigubernamental el NJM habia adquirido una base de apoyo entre los jóvenes desempleados y algunos sectores obreros, lo que determinó que algunos opinaran que el movimiento estaba listo para convertirse en partido y participar en las elecciones de 1976. Para estas elecciones, en las que por primera vez ejercían su derecho al voto los jóvenes entre 18 y 21 años el NJMse unió al GNPy a un pequeño partido de orientación conservadora, el del Pueblo Unido (United Peoples Party, UPP), bajo el nombre de Alianza del Pueblo, con una plataforma reformista. ${ }^{23}$ Los resultados confirmaron que los nuevos votantes apoyaban.al NJM, ya que el 84 por ciento de ellos votaron por la Alianza. ${ }^{24}$ En total ésta obtuvo el 48 por ciento de los votos frente al 52 por ciento de Gairy. ${ }^{25}$ En el parlamento, la representación quedó constituida con 9 bancas para el GULP, 3 para el NJM con Bishop como jefe de la oposición, 2 para el GNP y 1, para el UPP.6 Esta participación ampliada del sector opositor no representó políticamente ningún cambio pues la alianza se dividió y el gobierno utilizó distintas estratagemas para aprobar por mayoría aquello que le interesaba aprobar. ${ }^{27}$ Sin embargo, la estrategia de enfrentarse a Gairy a través de medios legales fue positiva para el NJM porque le sirvió para desacreditar el sistema y la confianza que en él todavía tenían ciertos sectores medios. ${ }^{28}$

Junto con su actividad legal, en el periodo posterior a los sucesos de 1974, el NJM creó grupos de apoyo en distintos pueblos y dos ramas es: peciales clandestinas, una para jóvenes y otra para mujeres. ${ }^{29}$ Estas células del partido llegaron a elegir representantes a un consejo nacional coordinador y organizaron consejos parroquiales. ${ }^{30}$ La participación de esta red hizo posible la preparación del movimiento revolucionario que estalló el 13 de marzo de 1979, con la captura de las barracas del pequeño ejército granadino situadas en True Blue, que permitió que los insurgentes se incautaran de armas y municiones para proceder a la toma de la estación de radio y al apresamiento de los miembros del gobierno de Gairy. ${ }^{31}$ La primera institución revolucionaria en funcionamiento fue, de esta manera, el Ejército Revolucionario del Pueblo, dirigido por Hudson Austin, y formado por el grupo inicial de partidarios de Bishop, más numerosos voluntarios que se le unieron en los primeros días. La segunda institución fue el Gobierno Revolucionario del Pueblo, establecido en forma provisoria y constituido por catorce

22 Fitzroy Ambursley, "Whither Grenada", en Susan Craig, ed. Contemporary Caribbean, Maracas, Tr., 1982, vol. 11, p. 437.

${ }^{23}$ Ibid.

24 Selwyn Ryan en Trinidad Express, abril 4, 1979.

2s David Renwick en Trinidad Express, marzo 22, 1979.

26 Ambursley, op. cit., p. 437; EPICA, p. 49-50.

27 Trinidad Express, febrero 21, 1978; Advocate News, mayo 26, 1978.

28 W. Richard Jacobs, The Grenada Revolution At.Work, St. Augustine, Tr., UWI, s.f., p. 7.

29 EPICA, op. cit., p. 48.

${ }_{30}$ Merle Hodge y Chris Searle, Is Freedom We Making, Barbados, Grenada Information Service, 1981, p. 42.

31 DaBreo, op. cit., p. 117-139. 
miembros, presididos por Bishop. ${ }^{32}$. Unos días después se anunciaba oficialmente la suspensión de la constitución y se daba inicio a un experimento sociopolítico que trataria de alterar las formas sociales y políticas legadas por los ingleses.

La respuesta de la población local al movimiento revolucionario fue de buen auspicio y los granadinos parecieron dispuestos a esperar que cumpliera lo que había manifestado en sus primeras proclamas radiales: "Esta revolución es por trabajo, por comida, por vivienda decente y servicios de salud y para un mejor futuro para nuestros hijos y nietos..." ${ }^{33}$ y también "el Gobierno Revolucionario del Pueblo se compromete a retornar al régimen constitucional en una oportunidad cercana y a nombrar una Asamblea Consultiva para consultar con todo el pueblo a fin de establecer una nueva constitución que reflejará los deseos y aspiraciones de todo el pueblo de Granada." 34 Estuvieran interesados en la promesa de un mejor nivel de vida o sólo en el saneamiento de la situación política, en general el clima fue de aceptación y esperanza. El hecho de que entre los miembros del nuevo gobierno figuraban representantes electos al parlamento como Bishop y Whiteman hizo que muchos se sintieran dispuestos a aceptar la solución revolucionaria por cuanto parte de sus líderes habían, de algún modo, adquirido legitimidad a través de un proceso electoral anterior. ${ }^{35}$

Desde la revolución de 1979 hasta fines de 1980 el gobierno del NJM pareció regirse por su declaración inicial según la cual se comprometia a retornar a un gobierno constitucional. ${ }^{36}$ Aunque procedió a declarar que el único cuerpo autorizado a dictar leyes era el gobierno revolucionario, nombró a Bishop primer ministro y estableció la Suprema Corte de Granada como órgano de apelaciones,${ }^{37}$ esta posición estaba muy lejos de los lineamientos del manifiesto fundador del NJM en 1973, donde se hablaba de "reemplazar el sistema político con un sistema realmente democrático y de base en el cual la gente de cada pueblo o parroquia y de la isla toda será capaz de ejercer el poder en su propio beneficio." ${ }_{38}$ Las Asambleas del Pueblo, según modelo tanzanio, que aparecian como parte del programa politico inicial del NJM, fueron ahora consideradas "algo anticuadas" $\mathrm{y}$, además, como una provocación para los sectores medios cuyo apoyo era necesario para el funcionamiento de la economía granadina. ${ }^{39}$ Poco a poco, sin embargo, las declaraciones fueron haciéndose más radicales y el 13 de marzo de 1981, segundo aniversario de la revolución, marcó oficialmente el inicio de una nueva etapa política con la decisión del gobierno de abrir al pueblo en general el ingreso a los grupos locales de apoyo y a las organizaciones de masa que el NJM había creado en la clandestinidad. De esta forma, los consejos parroquiales, iniciados en 19.78 como reuniones mensuales dentro del partido, se abrieron a toda la comunidad. El volumen de partici-

32 Trinidad Guardian, marzo 17, 1979.

${ }_{33}$ Da Breo, op. cit., p. 128.

${ }_{34}$ W. Richard Jacobs e Ian Jacobs, Grenada. The Route to Revolutions, St. Augustine,

Tr., UWI 1981, p. 149.

35 Advocate News, marzo 14, 1979

36 Selwyn Ryan sostiene en su "Grenada. Balance de la revolución", Revista Occidental, año I, núm. 4, 1984, p. 464, que si el NJM hubiera llevado a cabo estas elecciones todavía estaría en el gobierno.

37 Andrew Burgess, "Review of the Laws of Grenada", Bulletin of Eastern Caribbean Affairs, vol. 7 núm. 1, marzo-abril, 1981, p. 21.

${ }^{38}$ Citado en Jacobs, "Movement...", op. cit., p. 31.

39 Ambursley, op. cit., p. 445. 
pantes obligó a la división de cada parroquia en varias zonas y se crearon los consejos zonales. Simultáneamente se definieron estructuras especiales para trabajadores, campesinos, jóvenes y mujeres, organizaciones de masa que también tenían sus ramas a nivel parroquial y zonal. El propósito básico del sistema era proveer canales regulares de comunicación entre gobierno y pueblo y hacer que los dirigentes asumieran su responsabilidad en forma directa ante la población. Estas estructuras no llegaron a estar totalmente institucionalizadas, aunque se esperaba que se llevara a cabo la división de consejos parroquiales y zonales en grupos comunitarios para cada pueblo. ${ }^{40}$ En forma paralela se mantuvieron las declaraciones acerca de una futura constitución que recogería los resultados prácticos del experimento que se estaba llevando a cabo. ${ }^{41}$

Para el gobierno revolucionario la justificación de la necesidad de un nuevo sistema político residía en el fracaso del "modelo Westminster" que, en lugar de limitar al gobierno en el ejercicio del poder, habia contribuido a que el partido de turno monopolizara elementos claves como la maquinaria electoral y legal y el sistema policial y de defensa. ${ }^{42} \mathrm{Se}$ constituía así en la base de una "dictadura constitucional" que preservaba la forma pero no la sustancia del sistema, además de separar al pueblo de sus representantes, de forma que la actividad democrática devenía en un derecho de unos pocos representantes, sobre los cuales el pueblo no ejercía ningún control salvo durante algunos segundos cada cinco años, o sea cuando emitía su voto. ${ }^{43}$

Veamos ahora qué lugar ocuparon dentro del nuevo esquema los partidos políticos. Es evidente que no había objeto para una división bipartidista de los electores puesto que sus aspiraciones se canalizaban en forma directa hacia el gobierno a través de organizáciones de masa y grupos locales de apoyo. El papel del NJM, único partido con una función establecida, era el de actuar como eslabón entre gobierno y organizaciones, formando y educando a la población para su participación política. El NJM se organizó con un Comité Central que abarcaba distintos burós, de los cuales el Buró Político era el más importante. Desde comienzos de 1981 éste empezó a insistir en la necesidad de una mayor organización, disciplina y profundidad ideológica para el $\mathrm{NJM}^{44}$ De los otros partidos existentes al producirse la revolución, el GULP de Gairy y el GNP, el primero desapareció arrastrado por el desprestigio de su líder y porque más que un partido organizado era una agrupación de masa rural y líder reactivada periódicamente a efecto de las elecciones. El GNP intentó seguir funcionando pero con escaso éxito y, aunque insistió en que era necesario que Granada regresara a un gobierno constitucional, en general no presionó demasiado. ${ }^{45}$

Si tuviéramos que resumir los aspectos políticos del régimen del NJM entre 1979 y 1983, sus principales características serían: insistencia en un nuevo sistema político y en la experimentación con organismos de base y, a la vez, el mantenimiento de la constitucionalidad como fin deseable a largo plazo; el papel del NJM como "guía filosófi-

${ }^{40}$ Hodge \& Searle, op. cit., p. $42-43$ y EPICA, op. cit., p. $111-112$ y 114.

41 Insight, enero 1982, p. 11 y febrero 1982, p. 7; Caribbean Contact, julio 1983, p. 16.

42 Trinidad Guardian, abril 1, 1979.

${ }_{43}^{43}$ Hodge \& Searle, op. cit., p. 87.

44 Véase "The Alienation of Leninist Group Therapy", Caribbean Review, vol. 12, núm. 4 , otoño 1983 , p. 52.

45 Advocate News, octubre 25, 1980; Trinidad Express, noviembre 27, 1979. 
ca para el ejército y el estado"; el desplazamiento por carencia de sentido en el nuevo sistema de los otros partidos políticos; el debilitamiento de sectores sindicales asociados a esos partidos tradicionales y, en algunos casos, su rèmplazo por sindicalistas del $\mathrm{NJM}^{46}$ el control estricto de los medios de comunicación, que quedaron reservados parà el gobierno:47 una oposición interna vinculada a un proceso de desestabilización externo que recurrió a la acción terrorista ${ }^{48}$ y un alto nivel de militarización de la sociedad ya que al ejército se agregaron milicias populares.

En cuanto a política económica, el gobierno promovió una economia mixta con tres sectores claramente demarcados, el público, el privado y el cooperativo, justificada como una etapa de transición no capitalista al socialismo. ${ }^{49} \mathrm{El}$ sector público se encargó de crear la infraestructura para el desarrollo de los otros dos sectores. En esta tarea el gobierno granadino contó con el aporte de numerosos préstamos y donaciones internacionales, que le permitieron elevar sus inversiones de 41.5 millones de dólares del Caribe Oriental en 1980 a 73.8 millones un año más tarde. ${ }^{50} \mathrm{El}$ rubro principal de estas inversiones fue la construcción de un nuevo aeropuerto internacional en Point Salines, para permitir el. arribo directo de aviones grandes desde los países de origen de los turistas. Este proyecto, así como otros en educación, salud y vivienda necesitaban del influjo de fondos externos y éstos provinieron en su mayor parte de fuentes como la Unión Soviética, Cuba, Libia, la Organización de Paises Exportadores de Petróleo (OPEP) y la misma Venezuela. Por su parte, Estados Unidos trató de obstaculizar que fondos de origen estadunidense llegaran a Granada a través de agencias internacionales y regionales. ${ }^{51}$ El sector económico más afectado por el cambio de gobierno fue el del turismo, donde la propaganda negativa del gobierno norteamericano logró que se redujera la afluencia de turistas de Estados Unidos, aunque es justo reconocer que hubo una tendencia decreciente del turismo en general para todo el Caribe por problemas de la crisis internacional. ${ }^{52}$

En general, a pesar de la persistencia del desempleo, el desempeño de la economía granadina bajo el gobierno del NJM recibió en 1982 y 1983, respectivamente, el aplauso del Banco Mundial y del Fondo Monetario Internacional. El primero presentó un informe económico sobre Granada en el cual se destacaba el alza del estándar de vida desde 1978, que la inflación había sufrido el menor de los aumentos experi-

16 EPICA, op. cit., p. 62-63; Burgess, p. 23.

47 Trinidad Express, junio 21 y julio 4, 1981 ; dos análisis interesantes son Carl D. Parris, "Intereses comerciales, libertad de prensa y Grenada", El Caribe Contemporáneo, núm. 7, octubre de 1983, p. 66-76, y Ramesh Deosaran, "The role of the press in the Caribbean: Private Ownership and Public Responsability", Caribbean Review, vol. XIII, núm. 4, otoño 1984 , p. 16, 45-46.

${ }^{48}$ Perry Mars, "The Tactic of International Political De- stabilization and Its Impact on-Socialist Transformation in the Caribbean", Conference on Geopolitical Change in the Caribbean in the 80's, CEESTEM, México, marzo 15-19, 1982; EPICA, op. cit., p. 91; Advocate News, junio 24, 1980; Trinidad Guardian, agosto 10, 1981; Trinidad Express, junio 8, 1980 y mayo 14, 1980; Jamaica Daily Gleaner, mayo 12 y 18, 1980.

49 EPICA, op. cit., p. 75.

so People's Revolutionary Government of Grenada, Report on the National Economy for 1981 and the Prospects for 1982, St. George's Government Printing Office, 1982, p. 8.

st Anthony Payne et. al., Grenada. Revolution and Invasion, Nueva York, St. Martin's Press, 1984, p. 62.

52 Véase Caribbean Monthly Bulletin, vol. 16, núm. 1, enero 1982, p. 33 y núm. 10, oct. 1982, p. 7; The Caribbean and West Indies Chronicle, abril-mayo 1983, p. 17. 
mentados en el área y que el servicio de la deuda era también el menor de la región. ${ }^{53}$ En cuanto al FMI, éste aceptó, a pesar de la oposición de Estados Unidos, otorgar a Granada un préstamo de 14.1 millones de dólares sin condiciones, excepto recomendar un mejoramiento de las reservas internacionales mediante el aumento de las exportaciones y mayor atracción de turistas. ${ }^{54}$

Este experimento sociopolítico terminó en octubre de 1983, en circunstancias de todos conocidas, que se iniciaron con la división del NJM en una lucha de poder que culminó con el asesinato de Maurice Bishop y varios de sus partidarios, dando pie a la intervención militar de Estados Unidos y otros estados del Caribe de habla inglesa. ${ }^{55}$ Cuando las tropas de combate estadunidense abandonaron Granada en diciembre de 1983 dejaron detrás dos importantes armas de dominación: los paquetes de ayuda económica y los grupos de "operaciones sicológicas", ${ }^{56}$ de las cuales probablemente la primera tenga más impacto que la segunda. Luego de la invasión, la ayuda norteamericana, ausente en el periodo anterior, ha sido decisiva y se ha concentrado en tres áreas: ayuda de emergencia para solucionar problemas creados por el desembarco militar, fondos para completar el aeropuerto internacional, al que Estados Unidos se había opuesto hasta entonces, y para fomentar los cambios necesarios que incentivaran las actividades del sector privado. ${ }^{57}$

Si después de la intervención militar los problemas económicos eran prioritarios, también lo era el problema de crear o reactivar partidos políticos y llevar a cabo una campaña electoral en una situación de virtual ocupación, a fín de normalizar en forma rápida la vida política. Junto con el GULP y el GNP surgieron otros partidos, varios de los cuales se unieron con el último de los nombrados y constituyeron el Nuevo Partido Nacional (New National Party, NNP), dirigido por Herbert Blaize del GNP, una coalición de moderados y conservadores que se adjudicó 14 de los 15 escaños del parlamento en las elecciones de diciembre de $1984 .{ }^{58}$ El programa del partido vencedor propiciaba una reforma constitucional que hiciera a los parlamentarios más respetuosos de las necesidades de sus circunscripciones, la continuación de la ayuda estadunidense y la permanencia en la isla de una fuerza de ese origen hasta tanto se entrenara un contingente especial de la policia, pues el ejército habia sido disuelto. ${ }^{59}$ Una de las primeras medidas que se tomaron fue dar validez a las leyes aprobadas entre la suspensión de la constitución en 1979 y las elecciones de diciembre, así como aprobar un sistema de gobierno local que pretende recrear algo de los grupos locales de apoyo del NJM. ${ }^{60}$

La principal dificultad del nuevo gobierno electo a fines de 1984 radica en su carácter de coalición inestable, donde los tres partidos que

\$3 Payne et. al., op. cit., p. 24-25.

s4 lbid.

ss Sobre estos sucesos puede verse Bernard Diederich, "Interviewing George Louison", Caribbean Review, vol. 12, núm. 4, otoño 1983 y otros artículos en ese mismo número de Caribbean Review; Payne et. al., op. cit., p. 105-167; EPICA, Muerte de una revolución, Washington, 1984.

s6 V.S. Naipaul, "An Island Betrayed", Harper s, marzo 1984, p. 61-72.

57 USAI, "Grenada. One Year Later", Washington, 1984, p. 1.

58 Payne et al., op. cit., p. 192-193; Insight, enero 1985, p. 8.

59 Para más detalles véase la entrevista a Herbert Blaize en Insight, enero 1985, p. 10

${ }^{60}$ Látin America Regional Reports-Caribbean, 22 de febrero 1985, p. 8; Insight, sept. 1985 , p. 3 . 
constituyen la alianza aspiran a controlaria en su beneficio. Esto se nota, por ejemplo, en el hecho de que hasta fines de 1985 no se había conseguido nombrar un viceprimer ministro, cargo importantísimo si se considera la salud quebrantada de Blaize. ${ }^{61}$ En julio de ese mismo año hubo además un intento de una parte del gabinete ministerial de forzar al primer ministro a renunciar, intento que no tuvo éxito. ${ }^{62} \mathrm{La}$ reimplantación del sistema parlamentario de gobierno va así acompañada de una creciente debilidad del mismo en la cual el gobierno se mantiene apoyado en la ayuda estadunidense, la falta de alternativas políticas viables, la cercanía en el tiempo de los sucesos de 1983 con su impacto ñegativo y, en buena medida, un clima de apatía política entre la población joven de la isla ${ }^{63}$ En este grupo posiblemente sea donde, a medida que la generación pre NJM desaparezca de la escena política, se observará mejor la influencia del experimento revolucionario, la cual estará condicionada además por el éxito o fracaso del intento de regresar al sistema de gobierno parlamentario.

\section{Dominica}

El segundo estado asociado del Caribe inglés que obtuvo su independencia fue Dominica, una pequeña isla montañosa y de infraestructura escasamente integrada. El primer partido político de la isla fue el Partido Laborista de Dominica (Dominica Labour Party, DLP), reactivado en 1955 por una mujer, Phyllis Shand Allfrey, bajo la influencia del movimiento socialista "fabiano" inglés y que, en la práctica, se orientó hacia los sectores medios y bajos de la población. Desde su triunfo electoral en 1961 el DLP controló el gobierno hasta 1979 e inauguró en noviembre de 1978 su periodo independiente. Con el tiempo su mayor apoyo electoral se concentró en las áreas rurales, mientras en Roseau, única ciudad de importancia, se constituyó en 1968 el Partido de la Libertad de Dominica (Dominica Freedom Party, DFP), que prontc aglutinó, bajo el liderazgo de Mary Eugene Charles, a los sectores asociados al comercio. ${ }^{64}$

En la década de los setenta varios factores se combinaron para facilitar la pérdida del control gubernamental del DLP. Por una parte, el impacto negativo de la caída del precio de la banana, principal producto de exportación de la isla; por otra, desde la crisis petrolera de 19731974, el aumento del precio internacional del combustible también incidió negativamente sobre la situación económica general de su población. A nivel social las repercusiones más notorias se dieron entre los jóvenes desempleados, influidos por los sucesos del Poder Negro en Trinidad y por la difusión de grupos pertenecientes al movimiento Rastafari. En el nivel interno del partido, el ascenso del liderazgo de Patrick John en 1974 significó también el ascenso dentro del DLP de personajes que se vieron involucrados en acusaciones de corrupción y manejos turbios, además de dar a su gestión de gobierno un carácter más represivo.

Bill Riviere ha analizado los problemas de los jóvenes desempleados

61 Insight, marzo 1985 , p. 1 y noviembre 1985, p. 6.

62 Ibid, agosto 1985 , p. 1-2.

63 St. Louis Post-Dispatch, junio 10 y 13, 1984, por Jon Sawyer.

${ }^{64}$ Lindel Smith, "The Political Situation in Dominica", Bulletin of Eastern Caribbean Affairs, vol. 5, núm. 3, julio-ag. 1979, p. 20-31. 
de Dominica en los años setenta. ${ }^{65}$ Crecientemente, a partir de los meses finales de 1972, advierte un movimiento de "regreso a la tierra" entre ellos como producto del desencanto por el fracaso del Poder Negro, de la voluntad de vivir de forma más simple y comunal, según el ejemplo de los Rastafaris y, para algunos, de la necesidad de escapar de un medio ambiente que se tornaba más opresivo a medida que la policía y el gobierno identificaban a los jóvenes desempleados urbanos como una posible amenaza subversiva y comenzaban a hostigarlos. Fue en este periodo cuando, al refugiarse en la supuesta vida idílica de la montaña, muchos de estos jóvenes se vincularon al cultivo y tráfico de marihuana y a la violencia, por lo que el gobierno de Dominica aprobó en 1974 la legislación más represiva del Caribe de habla inglesa: la Ley de Asociaciones y Sociedades Ilegales y Prohibidas, que castiga con nueve meses de prisión el uso de ropas y cabellos al estilo Rastafari y, en su Sección IX, establece que no se llevará a cabo ningún procedimiento penal o civil contra quien mate o hiera a un miembro de una asociación ilegal que sea encontrado dentro de una casa. ${ }^{66}$

Desde su ascenso al gobierno en 1974 Patrick John estuvo asociado tanto con medidas represivas de carácter draconiano, como la ya señalada, como con manejos dudosos del poder gubernamental. Con los dos aspectos, represión y corrupción, puede relacionarse la creación de la Fuerza de Defensa de Dominica en 1975, considerada como un arma de control político del DLP pues su reclutamiento se basó principalmente en la afiliación partidista. ${ }^{67}$ Desde ese año datan también las relaciones de John con negocios no muy claros que tendian, por ejemplo, al otorgamiento de facilidades petroleras a compañías encargadas de proveer de ese combustible a Sudáfrica ${ }^{68}$ o a ceder tierras agrícolas a una compañía estadunidense con destino a la creación de una zona y puerto libres prácticamente sin control del gobierno insular. En ese ambiente se produjo el 3 de noviembre de 1978 la entrada de Dominica a la vida independiente, a pesar del desacuerdo de la oposición. ${ }^{69}$

A mediados de 1979 el descontento social existente, más el estilo politico de John, precipitaron una crisis que terminó con la caída del gobierno del DLP. Los acontecimientos se iniciaron con demandas de mejoras salariales de los empleados públicos, que fueron enfrentadas por la decisión de Patrick John de hacer aprobar en la legislatura medidas que prohibieran las huelgas en el sector público. ${ }^{70}$ Durante una manifestación de protesta en mayo, el gobierno recurrió a la Fuerza de Defensa que disparó contra los manifestantes, exacerbando aún más a la oposición. Se formó entonces un Comité para la Salvación Nacional, que agrupó a todos los opositores, y una huelga general forzó la renuncia de los ministros del gabinete y del mismo gobernador general, que debía su nombramiento al DLP?' Muchos vieron en estos sucesos, tan

${ }^{65}$ Bill Riviere, "Contemporary Class Struggles and the Revolutionary Potential of Social Classes in Dominica", en S. Craig, ed. Contemporary Caribbean, vol. II, p. 365-384.

*o En ibid., p. 378 se cita el texto en inglés de la Sección IX.

${ }^{67}$ Insight, enero 1981, p. 1.

${ }^{68}$ New York Times, agosto 12, 1979, por Jo Thomas.

${ }^{69}$ N.J.O. Liverpool, "The Politics of Independence in Dominica", Bulletin of Eastern Caribbean Affairs, vol. 4, núm. 2, mayo-junio 1978, p. 20-23.

${ }^{70}$ New York Times, agosto 12, 1979, Jo Thomas.

7 Lindel Smith, “Patrick John, Dominica and the Signs of the Time", Bulletin of Eastern Caribbean Affairs, vol, 5, núm. 2, mayo-junio 1979, p. 23-28 y p. 40; L. Smith, "The Political Situation..." op. cit., p. 20-31 y New York Times, agosto 12, 1979. 
cercanos a la toma del poder por el Movimiento Nueva Joya en Granada, una influencia directa de los acontecimientos granadinos.

Se instituyó entonces un gobierno interino presidido por Oliver Seraphin, exministro de agricultura de Patrick John, que habia sido el primero en renunciar luego de los sucesos de mayo. Es notorio que este gobierno no sólo agrupó a los partidos opositores sino también a mièmbros del que podríamos considerar derrocado DLP. ${ }^{72}$ La principal misión del gobierno interino consistía en llamar a elecciones en el término de seis meses pero, apenas en el poder, debió hacer frente a los problemas causados por el huracán David que, además de arrasar casas y caminos, dejando a una gran proporción de la población a la intemperie e incomunicada, afectó seriamente la producción agrícola de la isla.$^{73}$ La ayuda internacional, principalmente de Estados Unidos y Francia, ${ }^{74}$ tuvo repercusiones políticas pues a comienzos de octubre Seraphin obligó a dimitir a dos de sus ministros debido a que tenían "ideas comunistas" y los donantes internacionales necesitaban "entender la posición ideológica" del gobierno de Dominica. ${ }^{75}$

El proceso electoral de 1980 llevó al poder al DFP, que obtuvo 17 escaños de los 21 de la legislatura, y, por primera vez en el Caribe de habla inglesa, a una mujer a ocupar el cargo de primer ministro. ${ }^{76} \mathrm{El}$ primer año y medio de gobierno de Mary Eugene Charles ha sido quizás el periodo más agitado en la vida política de la isla desde su independencia por cuanto fue testigo de tres intentos para derrocarla y de un fesurgimiento de la violencia por parte de grupos asociados al cultivo de marihuana en las montañas. La agitación se inició con demandas de mejoras socioeconómicas de la Fuerza de Defensa en diciembre de $1980,{ }^{77}$ para continuar con el secuestro y asesinato de un prominente propietario de tierras blanco, padre del director de la oficina de información del gobierno, a manos de un grupo que la prensa identificó como Rastafari, que demandaba la libertad de compañeros arrestados durante una campaña para terminar con el cultivo de marihuana. ${ }^{78}$ Desde ese momento, aparentemente, el gobierno estaba a la espera de un movimiento para derrocarlo y, con ayuda de oficiales franceses con base en Point-a-Pitre, Guadeloupe, vigiló a Patrick John hasta detenerlo en marzo de 1981, junto con el comandante de la Fuerza de Defensa de Dominica, mayor Frederick Newton, por intrigar contra el gobierno. ${ }^{79}$ Esto fue acompañado por la disolución de la Fuerza de Defensa, a la que se había privado previamente de sus armas por sospechas de que algunos oficiales estaban entrenando a Rastafaris en su uso y aún entregándoselas a cambio de marihuana. ${ }^{80} \mathrm{El}$ segundo intento sobrevino un mes más tarde, cuando el Buró Federal de Investigaciones (FBI) de Estados Unidos detuvo a una banda de mercenarios que desde Nueva

72 L. Smith, "The Political Situation...," op. cit., p. 24.

${ }^{73}$ New York Times, agosto 31, 1979; Miami Herald, sept. 1, 1979; Financial Times, sept. 12, 1979, por Tony Cozier.

${ }^{74}$ Sobre la ayuda de ésta y su interés en Dominica véase Journal of Commerce, octubre $4,1979$.

${ }^{75}$ Lindel Smith, "Dominica: The Post 'Hurricane David' Period", Bulletin of Eastern Caribbean Affairs, vol. 5; núm. 4, sept. oct. 1979, p. 32-33; Financial Times, oct. 16, 1979.

${ }^{76}$ Desde 1975 era líder de la oposición en el parlamento; sobre su carrera política véase New York Times, dic. 1, 1980, Jo Thomas y Financial Times, julio 23, 1980.

$"$ Miami Herald, dic. 14, 1980.

${ }^{78}$ lbid., febrero $17,1981$.

${ }^{79}$ Ibid., marzo 8, 1981; Insight, marzo 1981 p. 1 y abril 1981, p. 3.

80 Latin America Regional Reports-Caribbean, 27 marzo 1981, p. 4. 
Orleans preparaba una invasión armada a Dominica ${ }^{81}$ En diciembre de ese mismo año tuvo lugar un ataque fallido de ex miembros de la Fuerza de Defensa contra la estación de policía de Roseau y contra la cárcel, a fin de liberar a Patrick John y otros conectados con el primer complot. ${ }^{82}$ En esta ocasión, Mary Eugene Charles indicó que la vinculación entre los distintos hechos estaba dada por intereses del crimen organizado de Estados Unidos que, en alianza con ciertos sectores politicos locales, buscaban utilizar la isla para el cultivo y refinación de drogas.

El gobierno del DFP aplicó una política económica modelada según la línea del FMI; al que debió recurrir desde principios de su periodo para solucionar problemas de balanza de pagos mientras se restauraba la base exportadora de la isla en los cultivos de bananas arrasados por el huracán David en 1979 y al año siguiente por el Allen. ${ }^{83}$.En cuanto a política exterior, también desde el primer momento se observó una clara alineación del gobierno del DFP con Estados Unidos, con respecto, por ejemplo, a los problemas planteados por la presencia del gobierno revolucionario granadino en la región. A fines de 1983 Mary Eugene Charles figuró en forma prominente en todos los sucesos que culminaron con la intervención armada en Granada.

En el campo político el DFP volvió a triunfar en 1985 frente a un DLP reagrupado. Este partido, a fines de 1982, experimentó la reunión de sus dos ramas - la de Patrick John y la de Seraphin-bajo el nombre de Partido Laborista de Dominica (Labour Party of Dominica, LP of Dominica) y el liderazgo de un ex ministro de finanzas, Michael $\overline{D o u}$ glas. ${ }^{84}$ Su bautismo de fuego fueron las elecciones locales a mediados de 1984 , cuando derrotaron al DFP, pero esto no se repitió a nivel nacional en 1985, pues el DFP obtuvo 15 de los 21 escaños -dos menos que en la elección anterior- y el LP, 6, entre ellos uno para Patrick John, quien en octubre de 1985 fue condenado a doce años de cárcel por conspirar para derrocar al gobierno. ${ }^{85} \mathrm{El}$ DFP basó su campaña electoral en la reactivación económica y en acusaciones de comunismo e interferencia extranjera a favor de la oposición, además de beneficiarse del apoyo de la jerarquía eclesiástica católica que utilizó su espacio radial para pedir a los votantes que no apoyaran a candidatos comunistas, ${ }^{86}$ algo importante en una isla como Dominica donde la radio es el principal medio de comunicación masiva debido al alto nivel de analfabetismo de la poblạción y donde el catolicismo es la religión con-mayor número de fieles, legado de la fuerte tradición francesa.

\section{Santa Lucia}

El primer partido político deSanta Lucía, el Partido Laborista de Santa Lucía (St. Lucía Labour Party, SLP ), se formó en 1950 a consecuencia del anuncio del gobierno británico de que, a partir del año siguiente,

81 Financial Times, abril 30, 1981; Miami Herald, mayo 7, 1981; The Caribbean and West Indies Chronicle, abril-mayo 1981, p. 5.

82 The Caribean and West Indies Chronicle, febrero-marzo 1982, p. 6.

${ }^{83}$ Journal of Commerce, febrero 11, 1981; The Caribbean and West Indies. Chronicle, dic.-enero 1982, p. 8 y 29.

84' Insight, febrero 1985, p. 4; Latin America Regional Reports-Caribbean, 30 sept. 1983, p. $3-4$.

ss Insight, marzo 1985, p. 6; julio 1985, p. 1 y nov. 1985, p. 6; Latin America Weekly Report, 5 julio 1985, p. 12.

${ }^{86}$ Insight, junio 1985 , p. 3. 
las elecciones serían según el principio del sufragio universal adulto. ${ }^{87}$ En esas elecciones obtendria 5 de los 8 escaños de la legislatura, iniciándose así la carrera política de George Charles, dirigente sindical de origen humilde. Su liderazgo fue, sin embargo, cuestionado bien pronto por John Compton, egresado universitario en los campos del derecho y la economia ${ }^{88}$ Esta lucha interna del partido impidió que éste cumpliera cabalmente su finalidad de representar los intereses de la clase obrera. En 1961 surgió, como producto de esta rivalidad, un segundo partido, el Movimiento Nacional Laborista (National Labour Movement, NLM ) de John Compton. Tres años más tarde la unión de este partido con el Partido. Progresista del Pueblo (People's Progressive Party, PPP) y dos parlamentarios disidentes del sLP permitió la constitución del Partido de los Trabajadores Unidos (United Workers Party, UWP), que, luego de ganar las elecciones de 1964, retendrían el poder durante quince años.

Se ha señalado como típico del comportamiento político de esta pequeña isla en el periodo entre 1951 y 1974 tanto un bajo nivel de participación electoral, atribuible al alto nivel de analfabetismo y a la apatía de los votantes, ${ }^{89}$ como al hecho de que el poder depende de las defecciones de uno a otro grupo y de las coaliciones que así se constituyen. ${ }^{90}$ Esto se advierte en la composición inicial del UW $\bar{P}$ y en que el SLP, para recuperar el control gubernamental en 1979, debió también recurrir a una coalición con elementos radicales asociados previamente con un grupo Forum. Esta coalición se había dado ya en vísperas de las elecciones de 1974 , donde la participación alcanzó el 82.9 por ciento ( 31 . por ciento más que en la elección anterior), ${ }^{91}$ justamente como consecuencia del vigor que inyectó en la campaña este nuevo grupo, nacido en el clima del Poder Negro y con vinculaciones con el NJM de Granada.

En el campo económico, los quince años de gobierno del UUP vieron importantes transformaciones en las cuales las principales fuentes de ingreso pasaron de la agricultura (azúcar y bananas) al comercio y turismo, ${ }^{92}$ al tiempo que la isla adquiria la que se consideraba la mejor infraestructura del Caribe Oriental de habla inglesa en términos de caminos y otras facilidades. Todo esto permitió que, a partir de 1972, con la instalación de su primer proyecto industrial de importancia, se iniciara la expansión de una industria manufacturera orientada a la exportación (plástico, cerveza, empaques de cartón, componentes electrónicos y otros). ${ }^{93} \mathrm{Si}$ esta politica tuvo éxito en atraer inversiones extranjeras y crear una infraestructura, no logró, sin embargo, mejorar las condiciones socioeconómicas de la población, para lo cual conspi-

${ }^{87}$ D. Sinclair DaBreo, of men and Politics, Castries, St. Lucia, CPI, 1981, p. 27.

s8 Ibid., p. 28-31; para más datos biográficos de Compton véase The Caribbean and West Indies Chronicle, junio-julio 1982, p. 15.

${ }^{89}$ El analfabetismo se estimaba entre 40 y 45 por ciento en 1982, según Caribbean Contact, junio 1982, p. 5; Patrick Emmanuel, "General Elections in St. 'Lucia, 1951-1974", parte I, Bulletin of Eastern Caribbean Affairs, sept.-dic. 1977 y parte II, Ibid., enerofebrero 1978.

90 Emmanuel, op, cit, parte II, p. 4-7.

91 Ibid., p. 9.

92 "St. Lucia", en Latin America and the Caribbean 1981-1982, Essex, World of Information, 1981 .

93 Rosemary Brana-Shute y Gary. Brana-Shute, "St. Lucia”, en Jack W. Hopkins, ed. Latin America and Caribbean Contemporary Record, vol. I, 1981-1982, Nueva York, Holmes \& Meier, 1981, p. 613-616. 
raron las premisas básicas de la política de "industrialización por invitación", basadas en una expansión lenta de sus beneficios, y realidades como una tasa de natalidad extremadamente alta y un analfabetismo también elevado. ${ }^{94}$ La crisis energética de 1973-1974 inició problemas con la balanza de pagos, más la aparición de inflación y un recrudecimiento del desempleo. ${ }^{95}$

La elección de 1979 puede considerarse la línea divisoria entre un periodo económico expansivo y de modernización acelerada y otro en el cual los desajustes internos del sistema se irian haciendo cada vez más claros. Además la obtención de la independencia política el 22 de febrero de 1979 hizo que ahora el control del gobierno adquiriera aún más interés para los partidos. Desde el momento en que políticos radicales como George Odlum y Peter Josie de Forum se unieron al SLP, contra Compton, las campañas asumieron un nuevo matiz de discusión ideológica y atrajeron a mayor número de votantes entre los jóvenes. ${ }^{96}$ Esto quizá haya influido para que se hicieran algunos manejos dudosos de las listas de votantes en 1974, cuando aparecieron registrados sólo 39815 nombres frente a 44868 cinco años antes. No se consiguió ocultar, de todas formas, que ya Compton y su partido habian perdido popularidad pues obtuvieron 10 de 17 bancas en comparación con 6 de 10 en 1969. Para 1979 los jóvenes entre 18 y 25 años representaban cerca del 80 por ciento de los votantes registrados y a ellos se atribuye el vuelco de la elección hacia el SLP, que obtuvo 12 de los 17 escaños.

El nuevo gobierno del SLP estuvo presidido por el conservador primer ministro Allan Louisy, pero con Odlum y Josie en ministerios claves. ${ }^{97}$ Las primeras medidas del gobierno fueron de carácter progresista, tales como el establecimiento de un sistema de salud subsidiado por el gobierno, el reparto gratis de libros de texto en las escuelas secundarias, la decisión del gobierno de asumir en forma directa la importación de renglones básicos como cemento y harina de trigo, e imponerles precios máximos. ${ }^{98}$ Sin embargo, el estallido de una lucha por el liderazgo entre Odlum y Louisy frustró la intención de estas medidas. El desacuerdo se originó cuando Louisy se negó a cumplir un arreglo previo a las elecciones, según el cual él abandonaría el cargo de primer ministro después de seis meses, para ser nombrado gobernador general, mientras Odlum le sucedería como primer ministro. ${ }^{99}$ La lucha interna se extendió por todo el gobierno hasta mayo de 1981, cuando Louisy renunció, y afectó tanto la aprobación como la implantación de medidas económicas urgentes en un periodo de creciente declinación de la etapa expansiva anterior. ${ }^{100}$ Winston Cenac, ex ministro del SLP, fue el encargado de formar un nuevo gobierno pero sólo consiguió mantener una tenue mayoría de un voto en la legislatura hasta enero de 1982.

A comienzos de 1982 se instaló el tercer primer ministro en apenas

94 Ibid.; Lindel Smith, "The St. Lucia Elections, 2nd julio, 1979", Bulletin of Eastern Caribbean Affairs, vol. 5, núm. 3, julio-agosto 1979, p. 4; Insight, octubre 1981, p. 8.

9s S.J. Best, "World Inflation and the St. Lucian Economy, 1970-1978", Bulletin of

Eastern Caribbean Affairs, vol. 4, núm. 4, sept.-oct. 1978, p. 8-11.

96 Este párrafo se basa en L. Smith, "The St. Lucia Elections...", op. cit.,

97 New York Times, agosto 13, 1979. Jo Thomas.

98 Insight, mayo 1980, p. 6-7; nov. 1980, p. 6.

99 Earl Bousquet, "An Analysis of the Present political Struggle in St. Lucia", Bulletin of Eastern Caribbean Affairs, vol. 6, núm. 1, marzo-abril 1980, p. 24.

100 Sobre este conflicto véase Miami Herald, nov. 22, 1980; Insight, abril 1981, p. 7 y DaBreo, Of Men and Politics, op. cit. 
dos años y medio de vida independiente, ${ }^{101}$ Michael Pilgrim, ex ministro del SLP pero de la facción de Odlum que habia salido de la coalición para formar el Partido Laborista Progresista (Progressive Labour Party, PLP). El nuevo gobierno tuvo carácter interino y la misión de llamar a elecciones en el término de seis meses. ${ }^{102}$ En él hubo representación del partido de Odlum, del SLP y del UWP, y el acuerdo sobre reparto de cargos y un código de conducta para la realización de las elecciones debió hacerse con la supervisión de directivos de la iglesia católica, la más influyente de la isla, por el nivel de animosidad imperante entre las partes. ${ }^{103}$

En mayo de 1982 los beneficiarios de la crisis y fin de la coalición fueron Compton y su partido que ganaron 14 escaños, el SLP, 2 y el PLP, 1. ${ }^{104}$ Pero, además, varios de los principales protágonistas de los sucesos de 1979 a 1982, Josie, Odlum, Cenac y Pilgrim, fracasaron en conseguir el apoyo electoral para asumir cargos en el nuevo parlamento. Se volvió asimismo a manifestar un alto nivel de abstención electoral, lo que indicaria la existencia de un número de votantes en disponibilidad que al parecer no creen en Compton. ${ }^{105}$ Las primeras medidas del nuevo gobierno estuvieron dirigidas a suprimir algunas reformas y nombramientos hechos por el SLP en su periodo, se volvió al pago por servicios en el hospital de Castries y se puso fin al control gubernamental sobre la importación de cemento, además de solicitarse a la corona británica la remoción del gobernador general Boswell Williams, nombrado por Louisy, que fue concedida. ${ }^{106}$ Pero resulta evidente que los principales retos del actual gobierno residen en el ámbito de la política económica, en una situación donde tanto el turismo como la producción bananera y la industria manufacturera han sufrido los efectos de la crisis mundial y de los desastres naturales, como el huracán Allen en $1980 .{ }^{107}$

Mientras tanto la oposición política parece estar a la espera del fracaso de Compton para surgir como una alternativa válida que pueda hacer frente al UWP en las urnas. Algunos analistas señalaban a fines de 1982 que existía la posibilidad de un realineamiento del sistema bipartidista entre el UWP, de derecha, y el PLP, de izquierda, por cuanto éste último había ganado más votos populares que el SLP y se creía que podía movilizar a los votantes que no participaron en la elección de ese año. Esta posibilidad se incrementaba al observarse que el SLP habia vuelto a enfrentarse internamente por el liderazgo entre Peter Josie y Neville Cenac, del ala más conservadora. Pero para 1985, el SLP se encuentra unificado bajo el liderazgo moderado de Julian Hunte y el PLP ha sufrido la deserción de muchos de sus miembros. ${ }^{108}$

101 R. Singh, Caribbean Contact, febrero 1982, p. 5.

102 The Caribbean and West Indies Chronicle, febrero-marzo 1982, p. 5.

${ }^{103}$ Insight, abril 1982, p. 1, 3-4.

104 The Caribbean and West Indies Chronicle, junio-julio 1982, p. 15.

10s Caribbean Contact, junio 1982, p. 5.

106 Latin America Regional Reports-Caribbean, 11 junio 1982, p. 3 y 10 dic. 1982, p. 6.

${ }_{107} \mathrm{La}$ industria manufacturera ha experimentado en los últimos años el cierre de varias compañías y una disminución de la mano de obra industrial en cerca de una tercera parte, The Caribbean and West Indies Chronicle, junio-julio 1982, p. 25-26 y ag.-sept. 1982, p. 25, Caribbean Contact, mayo 1982, p. 7; Insight, junio 1985, p. 9 y The Christian Science Monitor, Dennis Volman, dic. 8, 1983.

${ }_{108}$ Guy Ellis, "Compton: The Favorite for 1987 Polls", The Caribbean and West Indies Chronicle, oct.-nov. 1985, p. 11; para el análisis de 1982 véase Ibid., oct.-nov. 1982, 32. 


\section{San Vicente}

San Vicente y las Granadinas comprende, además de la isla mayor, otras siete pequeñas-Bequia, Canouan, Mayreau, Mustique, Prune Island, Petit St. Vicente y Unión Island, y hasta su independencia en octubre de 1979 se caracterizó políticamente por el enfrentamiento entre un partido populista y de raigambre sindical, dirigido por Ebenezer $\mathrm{T}$. Joshua, el Partido Político del Pueblo (People's Political Party, PPP) y otro más conservador, relacionado con sectores medios urbanos y educados, encabezado por un abogado, Milton Cato. ${ }^{109} \mathrm{~A}$ pesar de su enfrentamiento, en realidad no hay grandes diferencias entre los partidos, lo cual se hace más claro si se observa que entre 1961 y 1966, en una legislatura de 9 bancas, hubo once casos de parlamentarios que cambiaron de una "bancada" a otra. ${ }^{110}$ La consecuencia más evidente es que los gobiernos caen con relativa frecuencia haciendo necesarias nuevas elecciones y creando un climá de "intimidación y victimización" poco propicio para el desarrollo socioeconómico de la isla. ${ }^{111}$

En la década de los 70 surgió un tercer partido político, el Nuevo Partido Democrático (New Democratic Party, NDP), bajo la dirección de James Mitchell y con su base de apoyo popular en las islas Granadinas, que resentían la situación de postergación en que se encontraban frente a la preferencia de los distintos gobiernos por repartir sus favores entre los distritos de la isla mayor. ${ }^{12}$ En 1972 el NDP y el PPP formaron un gobierno de coalición que sufrió la misma suerte de los anteriores pues cayó en 1974, cuando Joshua presentó su renuncia forzando el fin de la coalición. ${ }^{113}$ Las elecciones de 1974 se caracterizaron por la proliferación de partidos, pues además de los tres ya existentes, surgieron una rama disidente del PPP llamada la "Junta", el Movimiento de Libertad Democrática (Democratic Freedom Party, DFP) y otros. De todos estos partidos el único que tenía algo nuevo que ofrecer era el DFP, que proponía reformas de tipo político con una asamblea para presentar y discutir recomendaciones al gobierno. ${ }^{114}$ El DFP, había nacido de un grupo Forum, y de elementos aún más radicales de este grupo surgió ese mismo año el Movimiento Unido de Liberación YOU. LOU (YOULOU United Liberation Movement, YULIMO), que no presentó candidatos en la contienda electoral. ${ }^{115}$

Las êlecciones de 1974 dieron el triunfo al partido de Milton Cato que no enfrentaba ninguna división interna y había aumentado su popularidad con sus críticas a la actuación del gobierno, favorecidas por los efectos de la crisis petrolera internacional sobre la economía local. El SVLP obtuvo 10 bancas de 13 y el 69 por ciento de los votos emiti-

109 Philip Nanton, "The Changing Pattern of State Control in St. Vincent and the Grenadines", en F. Ambursley y R. Cohen, eds. Crisis in the Caribbean. London: Heinemann Educational Books, 1983, p. 227.

"10 K.R.V. John, "Politics in a Small Colonial Territory: St. Vincent", citado en Nanton, op. cit., p. 228.

11 Neville Duncan, The Vincentian Elections 1974, Cave Hill, Barbados, ISER, UWI, 1975 , p. 1.

112 Nanton, op. cit., p. 228.

113 Duncan, op. cit., p. 3-14, estudia en detalle las razones de esta división.

114 Ibid., p. 22-23.

115 YULIMO, Independence for St. Vincent and the Grenadines, Kingstown, St. Vincent, YULIMO. 1979, p: 4. 
dos, frente a 2 bancas para el PPP (13 por ciento de los votos) y 1 de la "Junta" (con 16,4 por ciento de los votos). ${ }^{116}$

Pronto la cuestión central del nuevo gobierno fue la obtención de la independencia. Las posiciones de los distintos partidos al respecto han sido adecuadamente resumidas por Ralph Gonsalves, lider de YULIMO: ${ }^{117}$ para el gubernamental SVLP consistía en una oportunidad de mejorar sus posibilidades de obtener ayuda internacional a través de instituciones que sólo la otorgan a naciones independientes y además consideraba que la elección de 1974 le había dado un mandato para acceder a ella sin recurrir a elecciones generales previas ni a un referendum; el NDP se oponía a la independencia mientras el PPP la aceptaba y ambos deseaban elecciones o un referendum previo; por su parte, YULIMO y el DFM favorecían la independencia como una forma para" maniobrar mejor en el ámbito internacional y no consideraban necesario un referendum o elecciones. El proceso de obtención de la independencia se vio algo demorado por la erupción del volcán La Soufrière en abril de 1979, que dejó sin hogar a casi el 20 por ciento de la población y arrasó los cultivos de bananas y arrurruz, orientados hacia la exportación, así como la agricultura de subsistencia. ${ }^{118}$ Luego de la ceremonia oficial de independencia el 26 de octubre de 1979, Cato se apresuró a llamar a elecciones para diciembre de ese mismo año, a fin de aprovechar la popularidad que la independencia y los recursos de la ayuda internacional con motivo de La Soufrière daban a su partido. ${ }^{119}$

Las primeras elecciones después de la independencia contaron con la participación del SVLP, frente a los opositores NDP (Mitchell), PPP (Joshua) y un Movimiento Unido Popular (United People's Movement, UPM), de orientación socialista, basado en YULIMO, el DFP y otros, que presentaba un "liderazgo colectivo" dentro del cual resaltaba la figura de Gonsalves. ${ }^{120} \mathrm{El}$ mejoramiento relativo de la economía desde 1974 , sobre todo a medida que la producción de arrurruz conseguía mejores precios y mercados por su utilización en la fabricación de papel para computadoras, y la disminución del desempleo y el descontento vinculado a la decisión gubernamental de restablecer la industria azucarera, pueden explicar el triunfo del partido del gobierno con $11 \mathrm{de}$ 13 bancas y el 54.2 por ciento de los votos. ${ }^{121}$ Sin embargo, a pesar de este triunfo el SVLP recibió un 8.7 por ciento menos de votos que en 1974, aunque votó un 13 por ciento más de la población, lo que indica una pérdida de popularidad del partido. El NDP obtuvo las 2 bancas restantes con el 25 por ciento de los votos. La elección marcó el fin de la carrera politica de Joshua, cuyo partido no obtuvo ninguna banca y apenas un 2.2 por ciento del voto. ${ }^{122}$

Apenas producido el triunfo electoral del SVLP la prensa internacional se hizo eco de un intento de rebelión en Unión Island, llevado a cabo por un grupo de Rastafaris como forma de llamar la atención

116 Duncan, op. cit., p. 27.

117 Ralph Gonsalves, "The Independence Movement in St. Vincent", Bulletin of Eastern Caribbean Affairs, vol. 4, núm. 2, mayo-junio 1978, p. 16-20.

118 Financial Times, mayo 18, 1979.

11 Washington Post, nov. 8, 1979; Miami Herald, dic. 2, 1979; Narton, op. cit., p. 239.

120 Miami Herald, dic. 2, 1979; Financial Times, oct. 26, 1979, Tony Cozier; Nanton, op. cit., p. 238-239.

121 Lindel Smith, "The Vincentian Elections, Dic. 5, 1979", Bulletin of Eastern Caribbean Affairs, vol. 5 núm. 5, nov.-dic. 1979, p. 1-9.

122 Miami Herald, dic. 7, 1979; Insight, julio 1980, p. 6. 
hacia los problemas de desempleo y desinterés por parte del gobierno que enfrentaban las pequeñas islas y sus habitantes. ${ }^{123} \mathrm{La}$ represión del movimiento estuvo a cargo de la Fuerza de Defensa de Barbados, que se hizo presente a pedido del gobierno de San Vicente pues éste carecía de ejército. El segundo gobierno de Milton Cato se caracterizó por el deterioro de la economía, afectada por la baja internacional en los precios de las bananas, la competencia brasileña en la producción de arrurruz y el fracaso del intento del gobierno de participar en la actividad agrícola mediante la compra y puesta en funcionamiento de plantaciones abandonadas o descuidadas por sus dueños, ${ }^{124}$ además del impacto del huracán Allen, cuando apenas los cultivos estaban recobrándose de los efectos de la erupción de La Soufrière. ${ }^{125}$ Prosperó, sin embargo, la actividad financiera "offshore" de forma que para 1981 se habían registrado bajo esta modalidad cerca de 250 blancos, pero esto casi no generó empleo salvo para algunos abogados locales asociados a la actividad financiera.

También se instalaron algunas empresas manufactureras orientadas en general a la explotación del trabajo femenino que todavía en esta isla recibe una remuneración menor que la de los hombres por la misma actividad. ${ }^{126}$

Desde 1979 se han producido en el frente político una serie de reagrupamientos y cambios de liderazgo en los partidos nacionales. Asi en 1980 se produjo la separación de una rama del NDP, encabezada por Calder Williams, que fundó el Partido del Pueblo Trabajador (Working People's Party, WPP). ${ }^{127}$ En 1982 Gonsalves renunció como líder del UPM, cuando este partido se negó a entrar en tratos con el NDPpara construir un frente opositor unido; en septiembre de ese mismo año, Mitchell fue nombrado líder de la oposición en el parlamento. ${ }^{128}$ En 1981 ya el descontento con la situación socioeconómica había hecho eclosión en una serie de demandas a las cuales el gobierno respondió presentando un proyecto de legislación que, de haber sido aprobado, hubiera impuesto penas de multa y prisión para aquellos que afectaran servicios esenciales mediante huelgas. ${ }^{129} \mathrm{La}$ oposición se unió para enfrentar esta legislación y la presión popular obligó a Cato a dejarla en suspenso, mientras, a su vez, la policía de la isla recurría a una huelga sorpresiva a fin de presionar sus propias demandas salariales. ${ }^{130}$

En 1984 se produjo un nuevo llamado a elecciones que dio el control del gobierno al NDP, y a Mitchell el cargo de primer ministro. Al año siguiente una elección especial en la circunscripción representada por Cato, que renunció y se retiró de la vida política, permitió que el NDP ganara una nueva banca (ahora 10 de 13). ${ }^{131}$ En este nuevo periodo el gobierno de Mitchell parece haber centrado su atención en el problema del desempleo, crucial para una economia en la cual cerca del 40 por

123 Nanton, op. cit., p. 234; New York Times, dic. 9, 1979; Miami Herald, dic. 26, 1979.

124 Latin America Regional Reports-Caribbean, 30 sept. 1983, p. 2-3; Nanton, op. cit., p. 232-233.

12s New York Times, agosto 17, 1980.

126 "St. Vincent" p. 245-247 en Latin America and the Caribbean 1981-1982; Rosemary

yy Gary Brana-Shute, "St. Vincent and the Grenadines", en J.W. Hopkins, ed., 617-621.

127 Insight, may. 1980, p. 7.

128 Caribbean Monthly Bulletin, oct. 1982, p. 4; The Caribbean and West Indies Chronicle, oct.-nov. 1982, p. 34.

129 Insight, junio 1981, p. 7; Nanton, op. cit., p. 240.

130 Insight, julio 1981, p. 8 y agosto 1981 , p. 8-9.

131 Latin America Regional Reports-Caribbean, 22 febrero, 1985, p. 8. 
ciento de su mano de obra se encuentra inactiva. ${ }^{132}$ Una de las primeras medidas anunciadas fue el cierre de la industria azucarera gubernamental al finalizar la zafra de 1985, lo que dejaría más gente sin empleo; esta medida había sido sugerida por un grupo de expertos de la Organización para la Agricultura y la Alimentación (Food and Agriculture Organization, FAO), frente al hecho de que las deudas alcanzaban casi 42 millones de dólares del Caribe Oriental y que su ineficiencia era tanta que se requerían 12 toneladas de caña para producir una tonelada de azúcar y toda su producción no alcanzaba a cubrir las demandas del mercado interno. ${ }^{133}$ Debe destacarse al respecto que, cuando el Banco de Desarrollo del Caribe aceptó en 1977 financiar la restauración de esta industria en la isla, estaba consciente de que comercialmente no era una empresa viable pero decidió intentarlo porque contribuiría a mitigar el problema de la falta de empleo. ${ }^{134}$

Posiblemente el desencanto que se produce sobre el programa propuesto por el gobierno de Estados Unidos para paliar los efectos de la crisis, la llamada Iniciativa para la Cuenca del Caribe, explique en parte la actitud de Mitchell hacia ese gobierno, con el que se ha negado a participar en maniobras militares conjuntas en la región (Operación "Palma Exótica" en Santa Lucía en septiembre de 1985), por considerar que esto incrementa el nivel de militarización del área y que ningún nivel de defensa regional, por alto que sea, será capaz de manejar eternamente un desempleo del 40 por ciento. ${ }^{135}$ Está por verse, sin embargo, si esta posición devendrá en una actitud crítica e independiente o quedará como un simple gesto simbólico.

Es evidente que en todos los microestados cuya evolución sociopolítica posindependentista hemos analizado existe una situación de inquietud y descontento que se manifiesta de distintas formas. Según James Petras ${ }^{136}$ esta efervescencia es un fenómeno general producto de la crisis de todos los sistemas sociales representados en el Caribe y crea diferentes problemas de acuerdo con el sistema social en el cual se halla inserto cada estado. Todos los microestados analizados pertenecen al sistema social capitalista por razones históricas y geográficas. Su inserción dentro de este sistema corresponde al tipo de "orientación al mercado externo", que estaría tipificado por el modelo puertorriqueño. La aplicación rezagada del ejemplo de Puerto Rico, aunado al hecho de su independencia política, la escasez de recursos materiales y el menor tamaño de su población, hacen que estos microestados pasen por una situación especial, en la cual se recrean elementos de crisis que se dan en Puerto Rico pero también otros que les son propios. Si para Petras la crisis puertorriqueña es la de un país capitalista dependiente que se está desindustrializando, ${ }^{137}$ en estos microestados se da el mismo fenómeno en algunas industrias establecidas como pioneras en los años 60 y/o 70 pero junto con una crisis de transición de sociedad agrícola a industrial. Este proceso se advierte en una escala de situaciones, con Dominica más cerca de una crisis del segundo tipo y Santa Lucía más cerca del

132 Insight, febrero 1985 , p. 8-9.

133 Ibid, e Insight, julio 1985, p. 9.

134 Nanton, op. cit., p. 234.

135 Insight, agosto 1985 , p. 1 y 3 y septiembre 1985, p. 8.

136 James Petras, "The Crisis of the Market, Socialist and Populist Regimes: Puerto. Rico. Jamaica and Cuba", Ponencia presentada en Caribbean Studies Association, 6th Annual Conference, St. Thomas, USVI, mayo 27-30, 1981.

137 Ibid., p.22. 
otro extremo, pero también como dos caras de una misma realidad interna que afecta en forma desigual a las áreas urbanas y rurales, haciendo más difícil la toma de decisiones que sirvan al menos para mitigar los efectos de la crisis. Por otra parte, la falta de recursos gubernamentales y la independencia política hacen que los planes estatales encaminados a ayudar a los desempleados sean inexistentes o esporádicos y mucho menores que los que mantiene Estados Unidos en Puerto Rico, mientras los que se benefician de los mismos lo hacen a través de su vinculación clientelista con el partido de turno en el gobierno, exacerbando la competencia por obtener el poder.

Mucho se ha discutido sobre la cuestión de la viabilidad de los microestados, en general, y de los caribeños en especial, desde la disolución de la Federación de las Indias Occidentales en 1962. La viabilidad involucra la capacidad de subsistir y funcionar en un medio ambiente cambiante; en otros términos, ésta puede juzgarse por la medida en que un estado puede actuar como una "entidad autónoma" dentro del sistema internacional. Pero, a su vez, como bien lo han señalado distintos autores, ${ }^{138}$ cabe preguntarse en qué medida la no viabilidad es una función de la vía cultural seguida por una nación, más que, como lo preconizan los analistas metropolitanos, una consecuencia de recursos demográficos y materiales limitados. En este sentido Patrick Emmanuel sugiere que la imitación de instituciones formales del "modelo Westminster" con las oportunidades de patronazgo político que éste provee perjudica el logro de una mayor eficiencia y racionalización administrativa en estos microestados. En el sistema económico es fundamental además su dependencia estructural, no sólo de mercados y exportaciones únicas, sino más importante quizá, de un sistema de valores que refuerza un consumismo de los sectores medios y altos que los recursos del microestado hacen imposible. ${ }^{139}$ También Louis Lindsay ${ }^{140}$ ha señalado que el destacar el pequeño tamaño de las entidades insulares y su escasez de recursos constituyó un método de manipulación del colonialismo británico para estimular la creencia en la no viabilidad colectiva, de forma que se desarrollara un síndrome de dependencia y la necesidad de mirar hacia afuera en busca de salvadores o protectores. Esta manipulación simbólica se patentiza en las declaraciones del primer ministro de una Jamaica independiente, Alexander Bustamante, en 1962, cuando proclamó que el único rayo de esperanza para el futuro de esa nación estribaba en el establecimiento de una relación estrecha con Estados Unidos; pues la isla era demasiado pobre y su población demasiado analfabeta para sostenerse a sí misma. Lo que el desarrollo jamaiquino necesitaba era una inyección masiva de ayuda de los paises metropolitanos, pues era ilusorio pensar en la posibilidad de elevar la situación de la población de la isla sólo mediante el esfuerzo propio. $\mathrm{Si}$ este concepto lo emitía el líder político de Jamaica en 1962, puede considerarse cual será el de quienes están dando sus primeros pasos independientes veinte años después, en un mundo capitalista en crisis, sin los recursos naturales y humanos de Jamaica (bauxita y casi 2 millones de. habitantes en una superficie de 4.411 millas cuadradas). ${ }^{141}$

138 Patrick Emmanuel, "Independence and viability: Elements of analysis", en V. Lewis, ed. op. cit., p. 1-4.

${ }^{139}$ Ibid., p. 9.

140 Louis Lindsay, "Colonialism and the Myth of Resource Insufficiency in Jamaica", en V. Lewis, ed., op.cit., p. 47-61.

${ }^{141}$ Emmanuel, "Independence and Viability...," op.cit., tabla 1, p. 2. 
Estos conceptos han sido desarrollados algo más por Edwin Jones, ${ }^{142}$ quien indica que en toda la concepción imperial británica la viabilidad siempre estuvo condicionada a la existencia de un marco de referencia política según el "modelo Westminster" y, en el campo económico, según una relación dependiente de la metrópoli; esto fue lo que permitió justamente la monopolización externa de los recursos productivos de las islas e hizo que la ayuda concesionaria inglesa sustituyera al desarrollo de una política de nacionalismo económico. La falta de eficiencia administrativa también se vinculaba en esta interpretación con el hecho de que una sociedad pequeña carecía de los recursos humanos adecuados y en número suficiente como para ejecutar esa función de la mejor manera posible. Para Jones esa falta de eficiencia deriva del hecho de que la mayor parte de las instituciones administrativas son importadas y su administración sufre de "incongruencia entre medios y fines" por cuanto los recursos se encuentran fuera del control del gobierno local. De esta forma tanto el pequeño tamaño como la experiencia colonial son responsables de la falta de viabilidad. La idea central gira en torno al concepto de que los obstáculos para un desarrollo con sentido dentro de las posibilidades y opciones de un microestado son básicamente culturales.

Todos estos análisis del problema de los microestados y su viabilidad fueron realizados cuando Granada no era todavia independiente y señalaban algunos factores que conspiraban contra esa viabilidad, fueran éstos económicos, históricos o culturales. Hoy, luego de once años de vida independiente de Granada, siete de Dominica, seis de Santa Lucía y San Vicente, lo primero que resalta es que esos mismos factores siguen vigentes y que el único intento, aunque parcial, por alterar su vigencia, realizado en Granada entre 1979 y 1983, finalizó cuando elementos geopolíticos tomaron precedencia sobre toda otra consideración para terminar el experimento. La permanencia de esos factores se manifiesta en que estos países. son viables económica y políticamente mediante subsidios bajo la forma de ayuda multi o bilateral en términos concesionarios. Aun en épocas expansivas estos estados no pueden generalmente hacer frente a los gastos recurrentes de sus presupuestos. Esto es lo que nos ha llevado a hablar de la existencia de una viabilidad política subsidiada. Esta viabilidad, como capacidad de subsistir y funcionar adecuadamente en tanto entidad autónoma del sistema internacional, está indudablemente condicionada por las fuentes de subsidios existentes y por lo que quienes las manejan entienden como funcionamiento adecuado. Así la viabilidad política es subsidiada para mantener determinados patrones políticos y económicos, sancionados externamente. En este sentido, la experiencia de Granada sirve para confirmar este hecho por cuánto el gobierno revolucionario también fue subsidiado por una ayuda internacional en la que cambiaron las fuentes de los subsidios y, con esto, los condicionamientos.

Uno de los patrones políticos sobresalientes dentro del sistema social capitalista en que están insertos los cuatro microestados aquí estudiados es la estabilidad política o mantenimiento del statu quo. Esto ha originado en los últimos años ajustes e innovaciones que han reforzado su vinculación entre sí pero también con los centros de poder extrarregionales. El más notorio es la creación de la Organización de Estados

${ }^{142}$ Edwin Jones, "Bureaucracy as a Problem-Solving Mechanism in Small States: A Review in Terms of the Current Literature", en V. Lewis, ed., op.cit., p. 76-93. 
del Caribe Oriental en 1981. El aumento del conflicto social en la subregión, evidenciado en los intentos conspirativos de Dominica, el movimiento revolucionario de Granada y la violencia asociada con grupos vinculados al tráfico de drogas, han hecho que el aspecto de defensa y seguridad tenga prioridad sobre otros. El creciente armamentismo del Caribe Oriental como consecuencia de esta preocupación y la creación y refuerzo de fuerzas armadas prácticamente inexistentes antes, a su vez, implican riesgos para la estabilidad de los gobiernos de los microestados. Andrés Serbín considera que existe una tendencia a la "africanización de la dinámica política poscolonial", entendiendo por tal la desestabilización de la elite política surgida del proceso independentista por el creciente poder de las fuerzas armadas; ${ }^{143}$ esto es posible en la medida en que las primeras evidencien cada vez con mayor claridad su fracaso en hacer frente a las demandas socioeconómicas de la población y las limitaciones inherentes al modelo parlamentario transplantado se hagan más onerosas. Lo primero llevaría a agudizar el conflicto social, acelerando el proceso de descomposición y caída de gobiernos, con una sucesión de elecciones, u otras formas de afectar al sistema (huelgas, sabotaje, etc.) y las segundas se harían más evidentes en cuanto las fuerzas armadas sean llamadas a intervenir para reprimir las manifestaciones de ese conflicto.

En resumen, por lo tanto, un balance comparativo de la situación sociopolítica de Granada, Dominica, Santa Lucía y San Vicente demuestra que, a pesar de diferencias de grado en algunos aspectos, estos microestados comparten factores históricos, geográficos y de coyuntura internacional externa. Pero, además, su inserción de tipo "orientación externa" en el sistema social capitalista se ve complicada por la presencia simultánea de dos crisis - una de capitalismo dependiente que se está desindustrializando y otra de transición de sociedad agrícola a industrial-. Esto dificulta la toma de decisiones, especialmente porque carecen de algún factor diferencial que los torne más atractivos (recurso estratégico o mercado interior suficientemente grande o mano de obra calificada no sindicalizada) y lo único que hace que se les dé atención preferente en cuanto a la provisión de ayuda e inversiones es justamente lo que para muchos constituye también la fuente de sus males: su cercanía a Estados Unidos.

La cuestión de la viabilidad de los microestados había sido discutida ya por analistas de dentro y fuera de la región caribeña hace más de diez años cuando todavía no eran independientes. Pero, mientras ambos grupos coincidían en señalar su falta de viabilidad no lo hacían en cuanto a qué elementos obstaculizaban el logro de la misma. Para los autores metropolitanos eran su tamaño pequeño y la escasez o falta de recursos económicos; para los caribeños, la persistencia de un sistema de valores coloniales (Emmanuel), el síndrome de dependencia generado por la manipulación simbólica (Lindsay), la existencia de instituciones políticas y administrativas importadas y la falta de control del gobierno local sobre sus recursos (Jones). Hasta hoy, tanto los limitantes geográfico-económicos como los culturales siguen vigentes, salvo quizás en Granada entre 1979 y 1983 donde se hizo un intento por alterar

${ }^{143}$ Andrés Serbin, "El Caribe oriental: Las secuelas de Grenada", Nueva Sociedad, 76 marzo-abril 1985, p. 125-127 y "Crisis e intervención militar en Grenada", ponencia presentada en el II Simposio sobre el Caribe, AVECA, UCV-Facultad de Ciencias, nov. 1983 , p. 15 . 
los segundos. Todo esto ha llevado a lo que podríamos llamar viabilidad subsidiada, en la cual la ayuda metropolitana ha sido sustituida por la ayuda internacional multi o bilateral, y a una relación en que su otorgamiento es condicionado al mantenimiento de patrones políticos y económicos que las fuentes de esa ayuda consideran valiosos. Por una parte, esto ha producido una cierta medida de cooperación e integración entre los microestados pero, lamentablemente, al estar orientada en forma casi exclusiva al mantenimiento de la estabilidad política, ha hecho reforzar el aspecto de seguridad y defensa. Paradójicamente, el refuerzo del sector militar vinculado a este aspecto podria llevar a terminar con la alternancia electoral del sistema parlamentario que hoy en día constituye el basamènto de la estabilidad que se aspira a mantener.

Una reflexión final podría ser el preguntarnos qué papel juegan en esta situación las luchas de liberación y la democracia en los microestados del Caribe Oriental. ¿Acaso como un ideal o una esperanza cada vez más lejana a medida que los subsidios incrementan los condicionamientos y continúan deformando los valores culturales? o ¿como una realidad posible en cuanto la crisis de los sistemas sociales existentes demuestre con mayor claridad el fracaso de los mismos y la necesidad de construir opciones nuevas? Sólo el tiempo puede contestarnos esta pregunta pero, de cómo anticipemos nosotros la respuesta dependerá sin duda nuestra actitud hacia estos estados y su experiencia política posindependentista. 